\title{
Immunostimulatory effect of Fms-like tyrosine kinase 3 ligand on peripheral monocyte-derived dendritic cells and natural killer cells: Utilization for ovarian cancer treatment
}

\author{
NORIOMI MATSUMURA, MASAKI MANDAI, JUNZO HAMANISHI, KEN YAMAGUCHI, KEN FUKUHARA, \\ HARUHIKO YAGI, TOSHIHIRO HIGUCHI, KENJI TAKAKURA and SHINGO FUJII
}

Department of Gynecology and Obstetrics, Graduate School of Medicine, Kyoto University, Kyoto 606-8507, Japan

Received June 27, 2007; Accepted September 10, 2007

\begin{abstract}
Systemic administration of Fms-like tyrosine kinase 3 ligand (FLT3L) has been considered to be a major route of delivery for tumor immunotherapy because expression of its receptor, FLT3, was detected predominantly in hematopoetic progenitor cells. However, several studies indicate that FLT3L locally overexpressed in tumor or dendritic cells (DCs) also shows an anti-tumor effect. In the current study, we found that FLT3 expression is not present in monocytes but is instead induced in DCs through the differentiation process resulting from stimulation by GM-CSF and IL-4. Addition of FLT3L further augmented FLT3 induction and also increased CD40 expression in DCs, leading to enhanced induction of lymphoblastoid cell line-targeted cytotoxic Tlymphocyte response and CD107a mobilization in $\mathrm{CD}^{+} \mathrm{T}$ cells. Furthermore, FLT3L also induced FLT3 expression in peripheral blood NK cells that showed an enhanced response detected by CD107a mobilization. In a murine ovarian cancer model, locally expressed FLT3L showed anti-tumor effects. Collectively, the current study indicates that FLT3L has an immunostimulatory effect on peripheral blood cells and FLT3L targeted to mature peripheral blood cells may serve as a useful tool for cancer immunotherapy.
\end{abstract}

\section{Introduction}

Ovarian cancer is the most lethal of all gynecological malignancies (1), being responsible for approximately $50 \%$ of all deaths from female genital tract cancer. (2) In the past two decades, there has been an approximate $0.1 \%$ annual increase in the incidence of ovarian cancer. The majority (75-80\%) of

Correspondence to: Dr M. Mandai, Department of Gynecology and Obstetrics, Graduate School of Medicine, Kyoto University, Kyoto 606-8507, Japan

E-mail: mandai@kuhp.kyoto-u.ac.jp

Key words: tyrosine kinase, dendritic cells, GM-CSF, IL-4, immunotherapy ovarian cancer patients present with advanced-stage disease. Although the initial response to chemotherapy is high, the majority of patients with advanced stage ovarian carcinoma develop residual or recurrent disease, and approximately $75-80 \%$ of patients die within 5 years. (3) Thus, there is a need to develop new therapeutic approaches including immunotherapy for the management of this disease.

Since the first report of its anti-tumor effect (4), Fms-like tyrosine kinase 3 ligand (FLT3L) has been regarded as a promising molecule to enhance anti-tumor immunity, including ovarian cancer (5-7). To date, the function of FLT3L has mainly been examined in hematopoietic progenitor cells, as FLT3 is expressed almost exclusively in hematopoietic progenitor cells (8-11). FLT3L is known to cause proliferation of hematopoietic stem cells in vitro $(12,13)$ and as a result, systemic administration of soluble FLT3L, which increases circulating numbers of dendritic cells (DCs) and natural killer (NK) cells, enhances anti-tumoral and viral immunity in vivo (3,14-16). However, systemic FLT3L administration may also cause tolerance because of the increased number of immature DCs (17-20).

On the other hand, inoculation of tumor cells (22-25) and DCs (26) expressing membrane bound or soluble FLT3L in mice models enhances anti-tumor immunity, while local administration of FLT3L plasmids $(27,28)$ and soluble FLT3L (29) enhances local Th1 reaction. These facts indicate that FLT3L acts on peripheral blood cells, including DCs and NK cells. However, the activity of locally administered FLT3L is unknown.

Here we show that FLT3 expression is induced by differentiation of peripheral blood monocytes to DCs with GM-CSF and IL-4 in vitro. We also demonstrate that FLT3 expression is induced in NK cells by FLT3L addition in vitro. On the basis of FLT3 expression in these peripheral blood cells, we also show that FLT3L enhances CD40 expression in DCs, which causes enhanced induction of CTL activity, especially with CD40 ligand, and that FLT3L directly enhances NK activity. Importantly, we also show a localized anti-tumor effect of FLT3L in murine ovarian cancer. From these results, we suggest that FLT3L could be used ex vivo to improve the therapeutic effect of DC-based immunotherapy, and also could be used in vivo by local administration of FLT3L to enhance local immunity. 


\section{Materials and methods}

Cell lines. Lymphoblastoid cell lines (LCL) were generated from PBMCs taken from a healthy donor after obtaining their written consent, as previously described (30). LCL were maintained in RPMI-1640 medium (Nikken Biomedicals, Kyoto, Japan) supplemented with fetal bovine serum (10\%, vol/vol Iwaki, Funabashi, Japan) and penicillin-streptomycin (100 U/ml penicillin, $100 \mu \mathrm{g} / \mathrm{ml}$ streptomycin; Nacalai Tesque, Kyoto, Japan). K562 cells (kind gift from Department of Experimental Pathology, Institute for Frontier Medical Sciences, Kyoto University) were also maintained in RPMI1640 medium supplemented with fetal bovine serum and penicillin-streptomycin as described above. The murine ovarian cancer cell line, HM-1 (Riken Bioresource Center, Tsukuba, Japan), was maintained in $\alpha$-MEM (Invitrogen, Carlsbad, CA, USA) supplemented as described above.

Flow cytometry and antibodies. Flow cytometry was performed with FACScalibur (Beckton Dickinson, Franklin Lakes, NJ USA). Antibodies used were anti-human FLT3L goat polyclonal antibody from Sigma (St. Louis, MO, USA), FITCconjugated anti-goat rabbit antibody from DakoCytomation (Glostrup, Denmark) and anti-human mouse monoclonal antibodies from BD Pharmingen (Franklin Lakes, NJ, USA) including CD1a-PE, CD86-FITC, CD40-PE, CD83-FITC, HLADR-APC, CD107a-FITC and CD107a-PE; anti-human mouse monoclonal antibodies from BioLegend (San Diego, CA, USA) including FLT3-PE and CD14-FITC; anti-human mouse monoclonal antibodies from Beckman Coulter (Fullerton, CA) including CD56-APC, CD56-FITC, CD4FITC, CD8-APC, CD8-FITC and CD3-RD1; and mouse IgG1-FITC and IgG1-PE antibodies (both from Beckman Coulter) as isotype controls. In all flow cytometric assays, dead cells were excluded by 7-AAD (BD Pharmingen).

$R T-P C R$. RT-PCR was performed with a One Step RT-PCR kit (Qiagen, Hilden, Germany) according to the manufacturer's instructions. Specific primers for FLT3L were forward 5'TGG GTC CAA GAT GCA AGG CTT G-3' and reverse 5'TTG AGG AGT CGG GCT GAC ACT G-3'; for actin, forward 5'-CCG CAA AGA CCT GTA CGC CA-3' and reverse 5'-TGG ACT TGG GAG AGG ACT GG- 3'; and for FLT3, forward 5'-CAG TGG GTG TCG AGC AGT ACT C-3' and reverse 5'-AGC CGG TCA CCT GTA CCA TCT G-3'. PCR amplification was performed using the following conditions: denaturing at $94^{\circ} \mathrm{C}$ for $1 \mathrm{~min}$, annealing at $55^{\circ} \mathrm{C}$ for $1 \mathrm{~min}$, and extension at $72^{\circ} \mathrm{C}$ for $2 \mathrm{~min}$, for 30 cycles.

Transfection of FLT3L cDNA and confirmation of transfection-specific FLT3L expression. Retroviral vector plasmids containing human membrane-bound FLT3L cDNA [pL(FLT3L)SN] were kindly provided by Dr Broxmeyer (31). Empty plasmid vector pLXSN (BD Clonetech, Mountain View, CA, USA) was used as a control. These plasmids were transfected into K562 cells and the cells were selected and maintained with G418 (500 $\mu \mathrm{g} / \mathrm{ml}$, Nacalai Tesque). Transfection-specific membrane-bound FLT3L expression was confirmed by RT-PCR and flow cytometry. Transfected K562 cells were irradiated (100 Gy) prior to subsequent experiments.
In vitro generation and maturation of DCs with and without FLT3L stimulation. CD14-positive monocytes were collected from PBMCs with anti-CD14 microbeads (Miltenyi Biotec $\mathrm{GmbH}$, Bergisch Gladbach, Germany) according to the manufacturer's instructions. Monocytes were plated in AIM-V medium (Invitrogen) at a concentration of $5 \times 10^{5} / \mathrm{ml}$ on an untreated 6-well plate (Iwaki) supplemented with GM-CSF (500 IU/ml; Peprotech EC, London, UK) and IL-4 (100 IU/ml; Peprotech). Then, K562 cells prepared as described above or soluble human recombinant FLT3L (100 ng/ml; Peprotech) were added. Incubation was performed at $37^{\circ} \mathrm{C}, 5 \% \mathrm{CO}_{2}$, and $100 \%$ humidity for 5 days during which immature DCs were generated. In order to prepare DCs to stimulate lymphocytes, necrotic LCL were made after 4 cycles of freeze-thaw and pulsed to DCs (DCs: necrotic cells = 1:2) at the 5th day of culture, then PolyI;C (50 $\mu \mathrm{g} / \mathrm{ml}$; Invitrogen) was added at day 6. At day 8, PBMCs were added to DCs. In some experiments, tumor necrosis factor (TNF) $\alpha(200 \mathrm{IU} / \mathrm{ml}$; Peprotech) was added to DCs instead of PolyI;C to induce maturation. Purity (always $>95 \%$ ) and maturation of DCs were confirmed by flow cytometry with the antibodies as mentioned above. FLT3 expression in monocytes and mature DCs with and without FLT3L stimulation was examined by RT-PCR and flow cytometry.

Culture of PBMCs with and without FLT3L stimulation for the analysis of FLT3 expression in NK cells. PBMCs were cultured, supplemented with $10 \mathrm{IU} / \mathrm{ml}$ of IL-2 with or without soluble FLT3L to maintain T cells and NK cells. Seven days later, FLT3 expression was examined in various fractions of PBMCs (NK cells, T cells, and monocytes), with and without FLT3L stimulation, by RT-PCR and flow cytometry. FLT3 expression was also examined in freshly isolated PBMCs.

Stimulation of PBMCs with DCs. Monocyte-deprived PBMCs were incubated with prepared DCs at a ratio of $5 \times 10^{6}$ PBMCs to $1 \times 10^{6}$ DCs in $2 \mathrm{ml}$ AIM-V medium in a 6-well untreated plate at $37^{\circ} \mathrm{C}, 5 \% \mathrm{CO}_{2}$, and $100 \%$ humidity. Human recombinant CD40L (500 ng/ml, Peprotech) was added in some experiments. On the 2 nd day of incubation, human recombinant IL-2 (10 IU/ml, Peprotech) was added. Half of the medium was replaced using fresh medium containing $2 \mathrm{X}$ concentration of cytokines every 3 days. After 9 days of incubation, PBMCs were collected, washed, and incubated on ice for $30 \mathrm{~min}$ prior to use in the assays described below.

Assessment of target specific activation of $C D 8^{+} T$ cells or CD56 ${ }^{+} \mathrm{NK}$ cells with flow cytometry. Prepared PBMCs (effector) were added to LCL (target) at an E:T ratio of 2:1; i.e., $1 \times 10^{6}$ PBMCs were added to $5 \times 10^{5}$ LCL in $500 \mu 1$ of fresh AIM-V medium. Five hours later, cells were collected and the culture medium was assayed for IFN- $\gamma$ by ELISA. Cell surface expression of CD107a in effector cells was examined with flow cytometry. Briefly, collected cells were incubated on ice for $30 \mathrm{~min}$ with antibodies described above and washed twice. For flow cytometric analysis, viable lymphocytes were gated and the number of CD107a-positive cells in $\mathrm{CD}^{+}{ }^{+} \mathrm{CD}^{+}{ }^{+}$-positive or $\mathrm{CD} 6^{+}$-positive cells was measured. 
Figure 1. FLT3 expression was induced in monocyte-derived DCs and enhanced by FLT3L addition. (a) FLT3 gene expression was examined by RT-PCR (30 cycles). Left, CD 14+ monocytes separated from PBMCs. Right, monocyte-derived DCs. (b) FLT3 protein expression was examined by flow cytometry. Upper, monocyte-derived DCs. Lower, CD14+ monocytes separated from PBMCs. FLT3 expression was induced in DCs during generation from monocytes with GM-CSF and IL-4. (c) FLT3-PE positive gate was decided where $\%$ of positive events of isotype control was $0.2 \%$ (dot plots). When sFLT3L was added during the generation of monocytederived DCs, FLT3 expression in DCs was enhanced (bar graph). At least 3 experiments were performed independently and the graph shows mean $+\mathrm{SE}$. ${ }^{*} \mathrm{p}<0.05$.

a

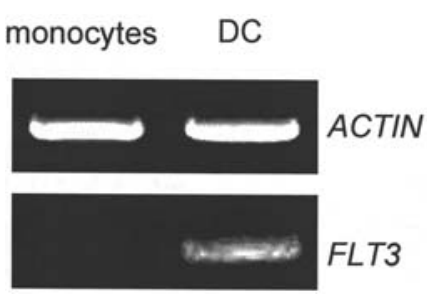

b
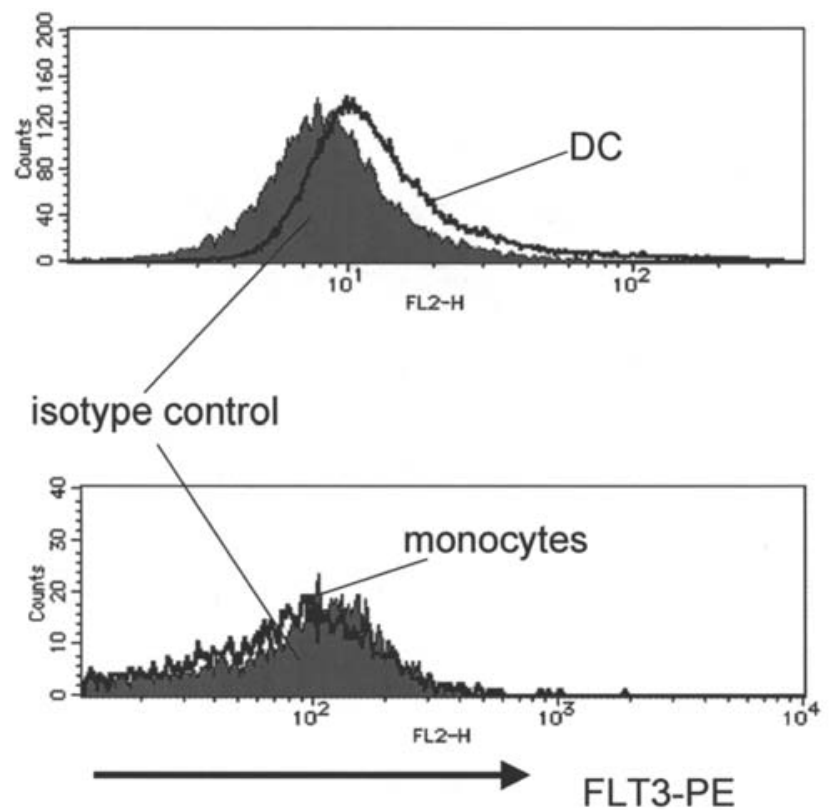

c
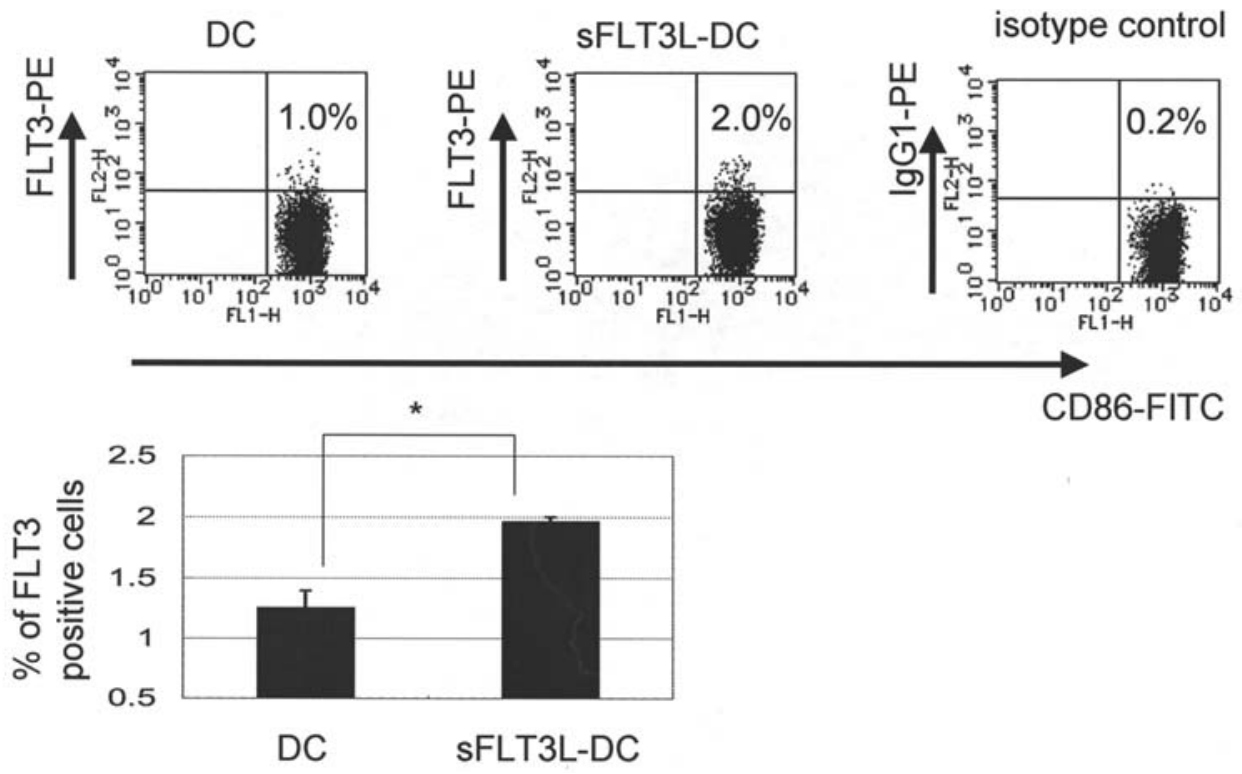

$I F N-\gamma$ ELISA. Culture medium prepared in experiments described above was assayed for IFN- $\gamma$ by ELISA (BioRad, Hercules, CA, USA) according to the manufacturer's protocol.

Flow cytometric cytotoxicity assay. Flow cytometric cytotoxicity assays were performed with CytoxyLux PLUS (Oncoimmunin, Gaithersburg, MD, USA). Briefly, target cells were stained with $\mathrm{T}$ Medium at $37^{\circ} \mathrm{C}$ for $1 \mathrm{~h}$ and washed. Prepared PBMCs were added to target cells at a variable E:T ratio and incubated in Caspase 3 substrate solution at $37^{\circ} \mathrm{C}$ for $1 \mathrm{~h}$. Then the reaction was stopped with washing buffer and cells were further washed. Stained target cells were detected with FACS at FL4, and apoptotic cells were detected at FL1.

Suppression of tumor formation. To examine the anti-tumor effect of locally administered FLT3L, irradiated FLT3L- transfected K562 cells $\left(5 \times 10^{6}\right)$ were mixed with HM-1 murine ovarian cancer cells and inoculated subcutaneously into $\mathrm{C} 3 \mathrm{~B} 6 \mathrm{~F} 1 \mathrm{mice}$, which is a hybrid strain of C3H/C57BL6 and syngeneic to HM-1 cells. Empty vector-transfected K562 cells were used as controls. In another experiment, FLT3Ltransfected K562 cells and HM-1 cells were inoculated separately into each side of the flank. Tumor size was measured in 3 dimensions twice a week until the long axis of the tumors exceeded $2 \mathrm{~cm}$. The animals received proper care according to the guidelines of the Kyoto University Committee on Animal Care. Animal experiments were performed in compliance with the United Kingdom Coordinating Committee on Cancer Research (UKCCCR) guidelines (Workman et al, 1988).

Statistical analysis. For analysis of between-group differences, P-values were determined using Mann-Whitney's U-test. A $\mathrm{P}$-value $<0.05$ was considered significant. 
a

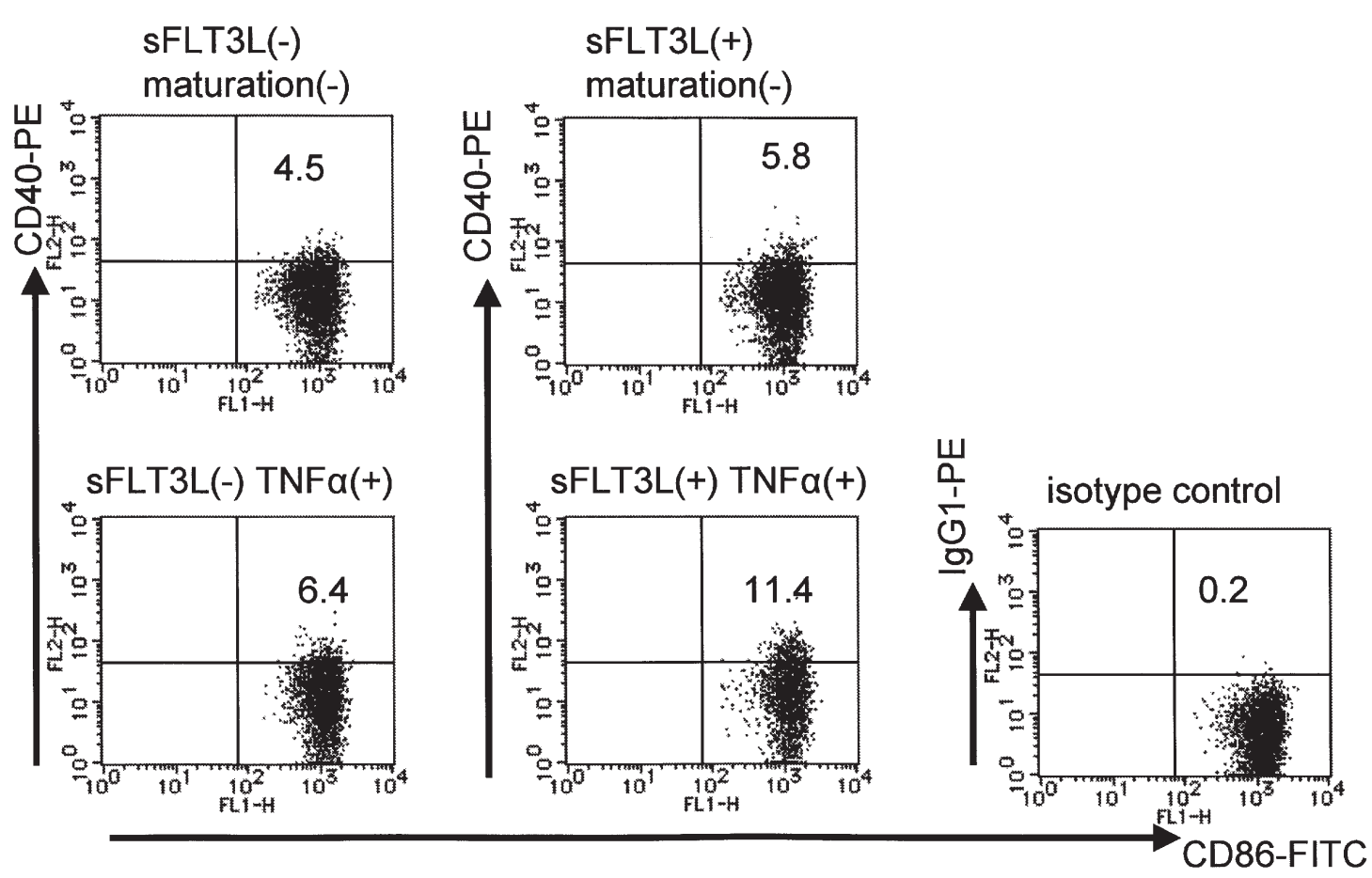

b
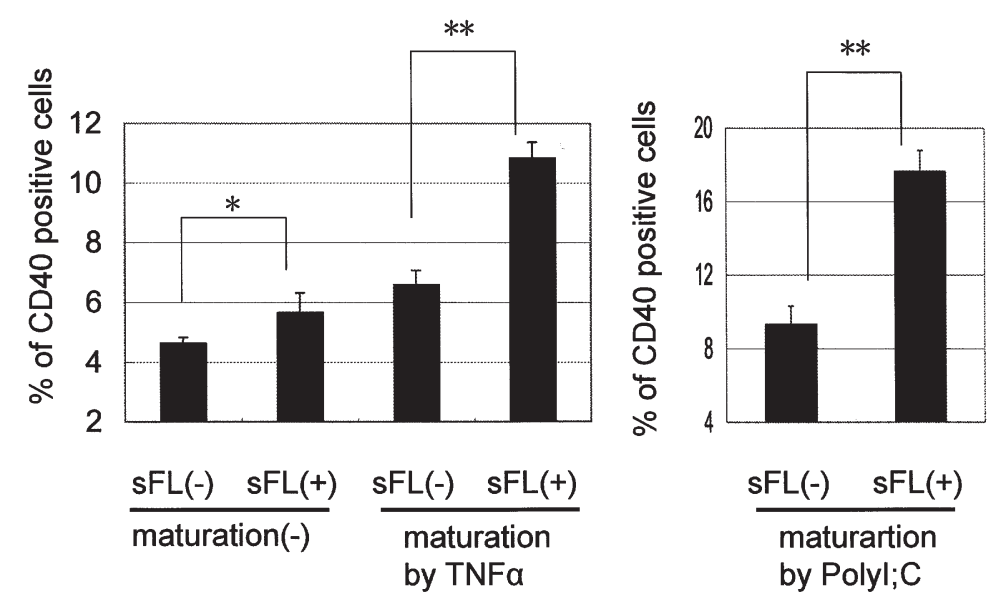

Figure 2. CD40 expression in DCs was enhanced by sFLT3L addition during the generation of monocyte-derived DCs. CD40 expression in DCs was examined. (a) Addition of sFLT3L during the generation of DCs and addition of TNFa to immature DCs changed CD40 positivity in DCs. CD40-PE positive gate was decided where $\%$ of positive events of isotype control was $0.2 \%$. (b) Left 2 bars, neither TNF $\alpha$ nor PolyI;C was added to immature DCs. Middle 2 bars, TNF $\alpha$ was added to immature DCs. Right 2 bars, PolyI;C was added to immature DCs. In these three different conditions, CD40 positivity in DCs was significantly increased by sFLT3L addition during the generation of monocyte-derived DCs. At least 3 experiments were performed independently and the graph shows mean + SE. sFL, sFLT3L. ${ }^{*} \mathrm{p}<0.05,{ }^{* *} \mathrm{p}<0.01$.

\section{Results}

Expression of FLT3 receptor in monocyte-derived DCs. As previously reported (8-11), no detectable FLT3 expression was observed in peripheral blood $\mathrm{CD} 14^{+}$monocytes by flow cytometry. (Fig. 1a and b) In contrast, when monocytes were differentiated to DCs by addition of GM-CSF and IL-4, FLT3 expression was induced in DCs (Fig. 1a and b). Furthermore, FLT3 expression in DCs was enhanced by addition of sFLT3L (Fig. 1c).

Impact of FLT3L on CD40 expression in DCs. DCs were generated from peripheral blood $\mathrm{CD} 14^{+}$monocytes by addition of GM-CSF and IL-4 with or without FLT3L. CD40 expression was examined before and after maturation, which was induced by either TNF or PolyI;C. The expression of CD40 in DCs was uniformly enhanced by sFLT3L addition (Fig. 2b). CD86 and HLA-DR expression in DCs was also examined. CD86 expression appeared stronger in sFLT3L-treated DCs, but this was not statistically significant (data not shown). HLA-DR expression was not changed with sFLT3L (data not shown). $m F L T 3 L$ was transfected into K562 cells (Fig. 3a and b). Next, K562 cells were irradiated and added during the generation of DCs, and the effect of mFLT3L signal was examined. CD40 expression in DCs was enhanced by mFLT3L with or without maturation (Fig. 3c). 
a

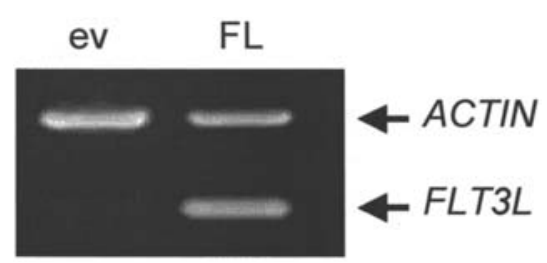

b

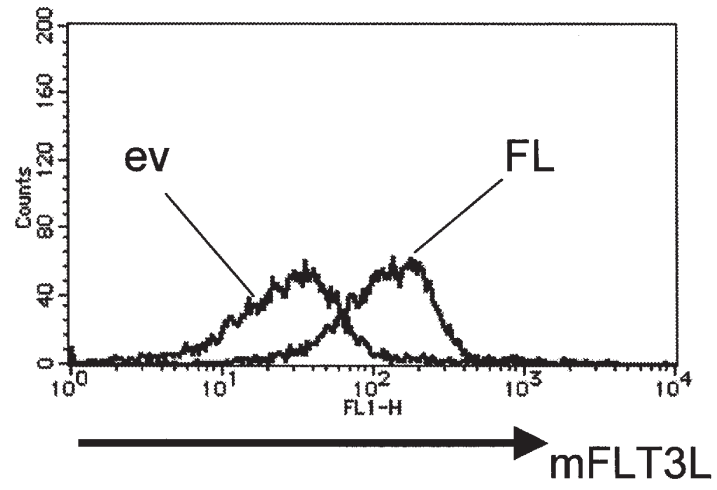

c

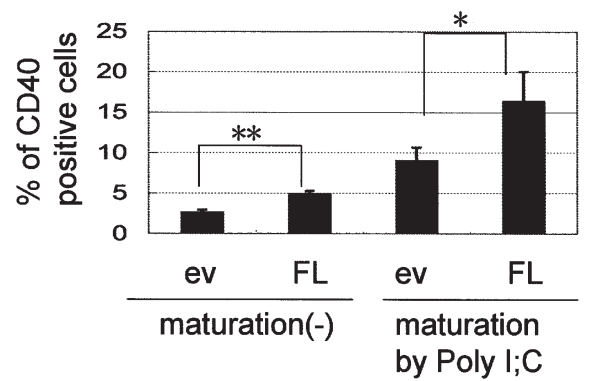

Figure 3. CD40 expression in DCs was enhanced by $m F L T 3 L$ stimulation during the generation of monocyte-derived DCs. Plasmids containing mFLT3L cDNA or empty vector were retrovirally transfected into K562 cells. (a) Forced expression of mFLT3L in K562 cells was confirmed by RT-PCR. (b) Forced expression of mFLT3L in K562 cells was confirmed by flow cytometry. (c) K562 cells were irradiated and added during the generation of monocyte-derived DCs. CD40-positive DCs were significantly increased by mFLT3L stimulation with or without maturation by PolyI;C. At least 3 experiments were performed independently and the graph shows mean $+\mathrm{SE}$. ev, empty vector-K562; FL, mFLT3L-K562. ${ }^{*} \mathrm{p}<0.05,{ }^{* *} \mathrm{p}<0.01$.

Influence of mFLT3L stimulation to monocyte-derived DCs on the ability to induce CTL activity in vitro. In order to examine the effect of FLT3L on the ability of DCs to induce CTL in vitro, we checked LCL specific cytotoxic activity. Briefly, $m F L T 3 L$-transfected and irradiated K562 cells were added during the generation of monocyte-derived DCs. DCs were pulsed with necrotic LCL and matured with PolyI;C. Then PBMCs were cocultured with the DCs for 9 days. PBMCs (effector) were then incubated with LCL (target) for $5 \mathrm{~h}$ and the IFN- $\gamma$ concentration in the supernatant was measured by ELISA. Stimulation by $m F L T 3 L$-transfected K562 augmented DC-induced IFN- $\gamma$ secretion from PBMCs (Fig. 4).

To directly assess CTL activity against LCL, we examined CD107a mobilization in CD8 ${ }^{+} \mathrm{T}$ cells. CD107a mobilization is a sensitive marker to assess CTL activity (32-34). PBMCs used in Fig. 5 were collected and CD107a expression was examined. Stimulation of DCs with $m F L T 3 L$-transfected K562

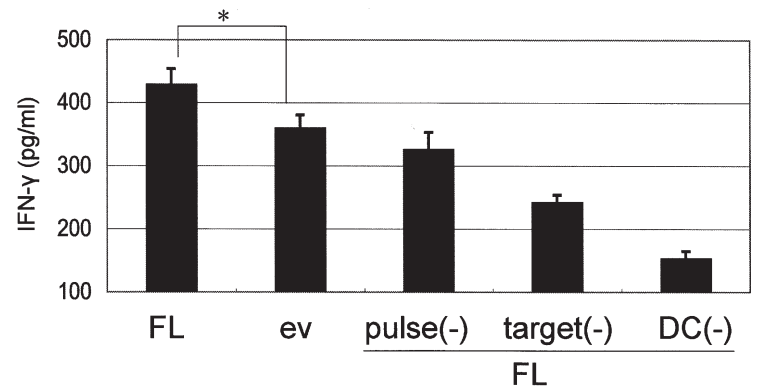

Figure 4. mFLT3L stimulation to DCs enhanced IFN- $\gamma$ secretion from PBMCs which were cocultured with DCs. K562 cells used in Fig. 3 were added during the generation of monocyte-derived DCs and the effect of forced expression of FLT3L was examined. DCs were pulsed with necrotic LCL and matured with PolyI;C. Then PBMCs were co-cultured with the DCs for 9 days. PBMCs (effector) were then incubated with LCL (target) for $5 \mathrm{~h}$ and the IFN- $\gamma$ concentration in the supernatant was measured by ELISA. Left 2 bars, FLT3L significantly increased IFN- $\gamma$ secretion from PBMCs. Right 3 bars show controls with FL (DCs were not pulsed, target was not added, and DCs were not added), which were also significantly lower than the FLtreated sample shown at the far left. At least 3 experiments were performed independently and the graph shows mean + SE. FL, mFLT3L-K562; ev, empty vector-K562. ${ }^{*} \mathrm{p}<0.05$.

modestly increased the rate of CD107a-positive $\mathrm{CD} 8^{+} \mathrm{T}$ cells (Fig. 5). IFN- $\gamma$ secretion from PBMCs detected by ELISA as well as the rate of CD107a-positive $\mathrm{CD}^{+} \mathrm{T}$ cells were significantly lower when DCs were not pulsed, or targets were not added, or DCs were not added (Figs. 4 and 5).

Cytotoxic activity of PBMCs against LCL was examined using a commercially available flow cytometric cytotoxicity assay kit. This kit detects intracellular activated caspase 3 in target cells. The percentage of apoptotic target cells did not significantly increase even when effector PBMCs co-cultured with mFLT3L-stimulated DCs were used (Fig. 6b, left). Because FLT3L increased CD40 expression in DCs, we tried to add CD40L when PBMCs were incubated with DCs. In this case, as shown in Fig. 6b, mFLT3L stimulation enhanced the ability of DCs to induce cytotoxic activity of PBMCs. Similar results were obtained with sFLT3L (Fig. 6c).

Influence of FLT3L on peripheral blood CD56+ cells. The influence of FLT3L signal on peripheral blood CD56 ${ }^{+}$cells was examined. FLT3 receptor mRNA expression in PBMCs was not detectable by RT-PCR (30 cycles) (Fig. 7a). This is in accordance with previous reports (8-10). However, when PBMCs were incubated with sFLT3L for 7 days, FLT3 mRNA was detectable using the same RT-PCR conditions (Fig. 7a).

The $\mathrm{CD}^{+}, \mathrm{CD}^{+} 6^{+}$, and $\mathrm{CD} 14^{+}$fraction of PBMCs in which expression of FLT3 mRNA was induced with the addition of sFLT3L was examined by FACS analysis. CD56 ${ }^{+}$cells showed expression of FLT3 after the addition of sFLT3L (Fig. 7b), while no detectable FLT3 expression was found in $\mathrm{CD}^{+}{ }^{+} \mathrm{CD}{ }^{+}$cells, $\mathrm{CD} 3{ }^{+} \mathrm{CD} 4{ }^{+}$cells, and $\mathrm{CD} 14^{+}$cells by flow cytometry (data not shown).

Irradiated $m F L T 3 L$-transfected or empty vector-transfected K562 cells were added to PBMCs, incubated for 7 days, and the percent of CD107a-positive $\mathrm{CD}^{+} 6^{+}$cells against LCL was examined. As shown in Fig. 7b, mFLT3L increased the proportion of CD107a-positive $\mathrm{CD}^{+} 6^{+}$cells. This positivity was not markedly increased when DC were added during the 
$\mathbf{a}$

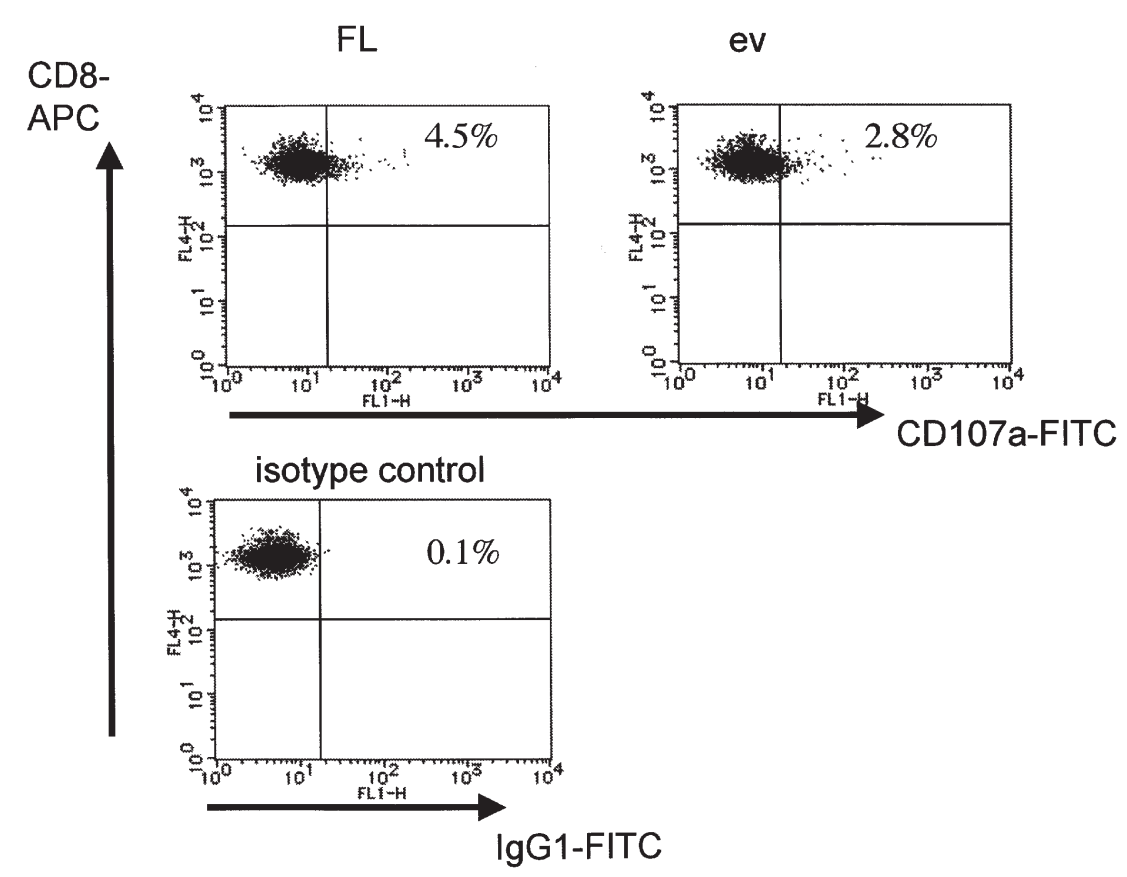

b

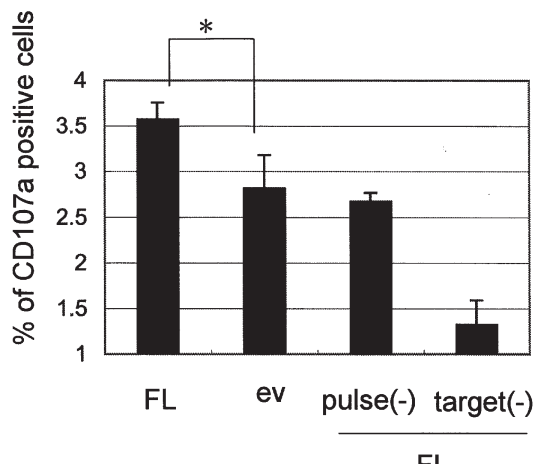

FL

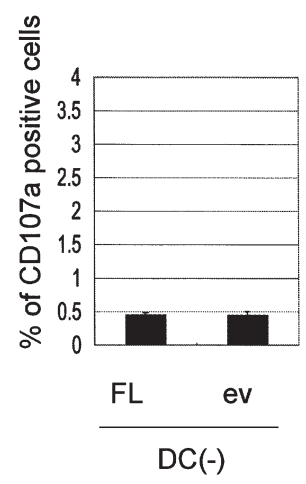

7-day incubation (data not shown). Though K562 cells are established targets of NK cells, CD107a-positive CD56+ cells were scarce without target LCL after the 7-day incubation (Fig. 7c).

Anti-tumor effect of $m F L T 3 L$. The potential anti-tumor effect of mFTL3L was examined using a murine ovarian cancer model. HM-1 is an ovarian cancer cell line derived from a B6C3F1 mouse and readily forms tumors when inoculated into B6C3F1 mice (Fig. 8a). Irradiated mFLT3L-K562 cells or empty vector-K562 cells were mixed with HM-1 cells and inoculated subcutaneously in B6C3F1 mice. When inoculated with mFLT3L-K562 cells, tumor growth of HM-1 cells was remarkably suppressed (Fig. 8a). We next determined whether the anti-tumor effect of mFLT3L-K562 cells is truly a local effect. Tumor growth of HM-1 was not suppressed when mFLT3L-K562 cells were administered at a different site (Fig. 8b).

\section{Discussion}

FLT3 is a tyrosine kinase receptor structurally related to the macrophage colony-stimulating factor receptor, c-FMS, and
Figure 5. mFLT3L stimulation to DCs enhanced the ability of DCs to induce activated CTL. PBMCs used in Fig. 4 were analyzed by flow cytometry. (a) CD107a-FITC-positive cells in $\mathrm{CD} 3^{+} \mathrm{CD} 8^{+}$lymphocytes were examined. The positive gate was decided where $\%$ of positive events in isotype control was $0.2 \%$. (b) At least 3 experiments were performed independently and the graph shows mean + SE. Controls with FL (DCs were not pulsed, and target was not added) were also significantly lower than the FL-treated samples shown at the far left. Two bars in the right graph show that CTL activity against LCL was low without DCs. FL, mFLT3L-K562; ev, empty vectorK562. ${ }^{*} \mathrm{p}<0.05$.

to the stem cell factor receptor, c-KIT. Its ligand, FLT3L, is a pluripotent hematopoietic growth factor, which contributes to maintenance, expansion, mobilization and differentiation of hematopoietic progenitor cells (35). Systemically administered FLT3L especially increases the numbers of DCs and NK cells in the blood and the lymphoid and parenchymal organs $(36,37)$ such as spleen and lymph nodes in mice and humans $(38,39)$. Both the membrane-bound and soluble isoforms of FLT3L are biologically active and stimulate the tyrosine kinase activity of FLT3 $(22,23)$. Mice lacking the flt 3 ligand by targeted gene disruption are viable but have severe defects including reduced cellularity in the hematopoietic organs, reduced numbers of myeloid and lymphoid progenitors in the bone marrow, and a marked deficiency of NK cells and DCs in lymph nodes, spleen, and thymus (40).

In vitro effects of FLT3L on progenitor cells have also been studied extensively. FLT3L, in synergy with other growth factors, induces marked proliferation of precursors of both myeloid and lymphoid lineages (37). In contrast, the in vitro effects of FLT3L on mature peripheral blood cells have received less attention (41). It is believed that FLT3 expression is confined mainly to progenitor cells, and its expression has not been observed in monocytes in the physiological condition 
a
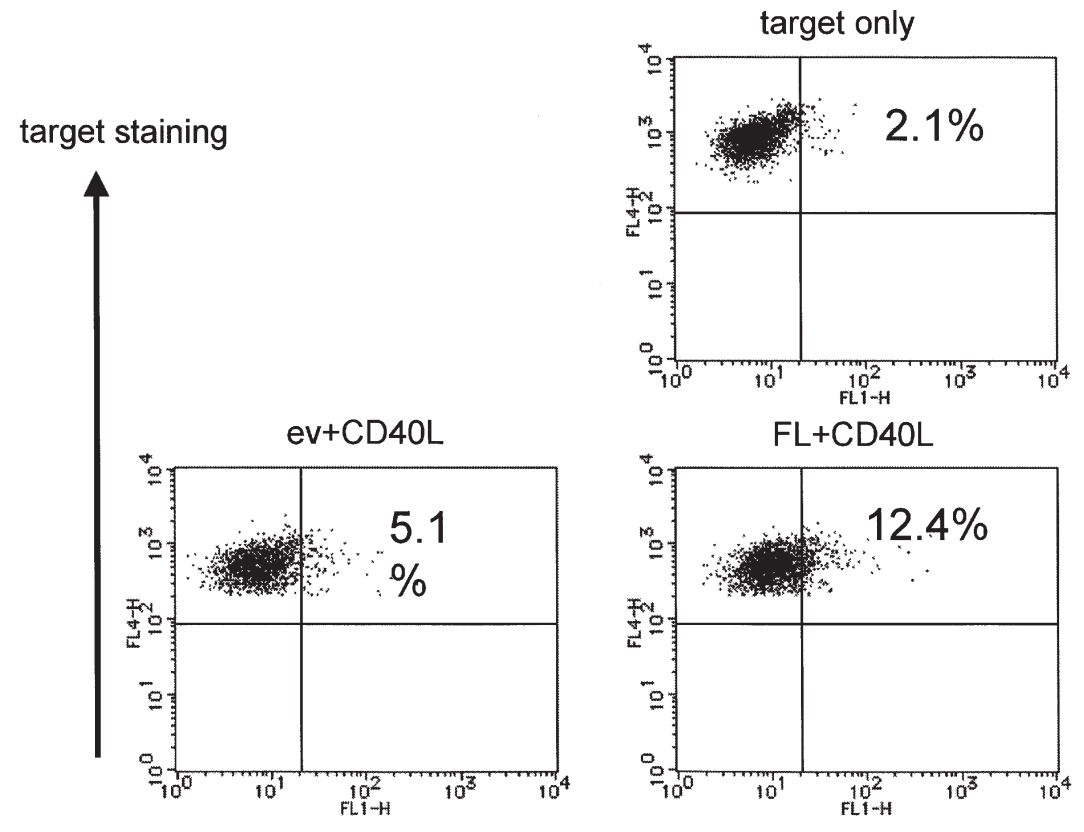

activated caspase 3

b
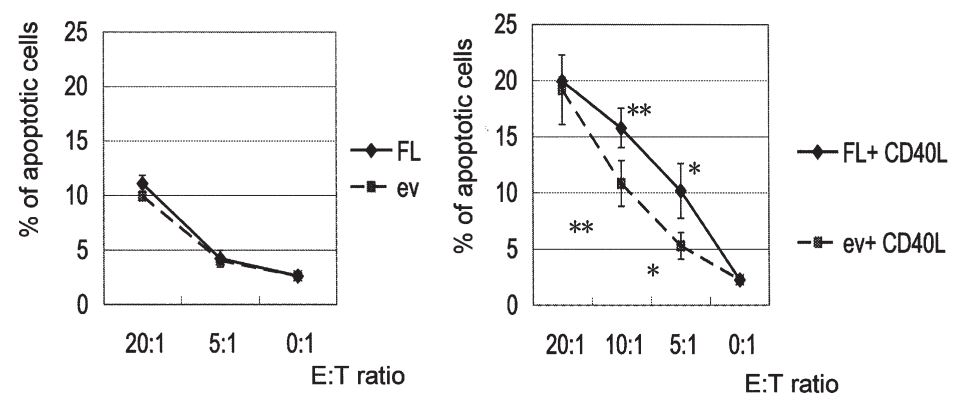

c
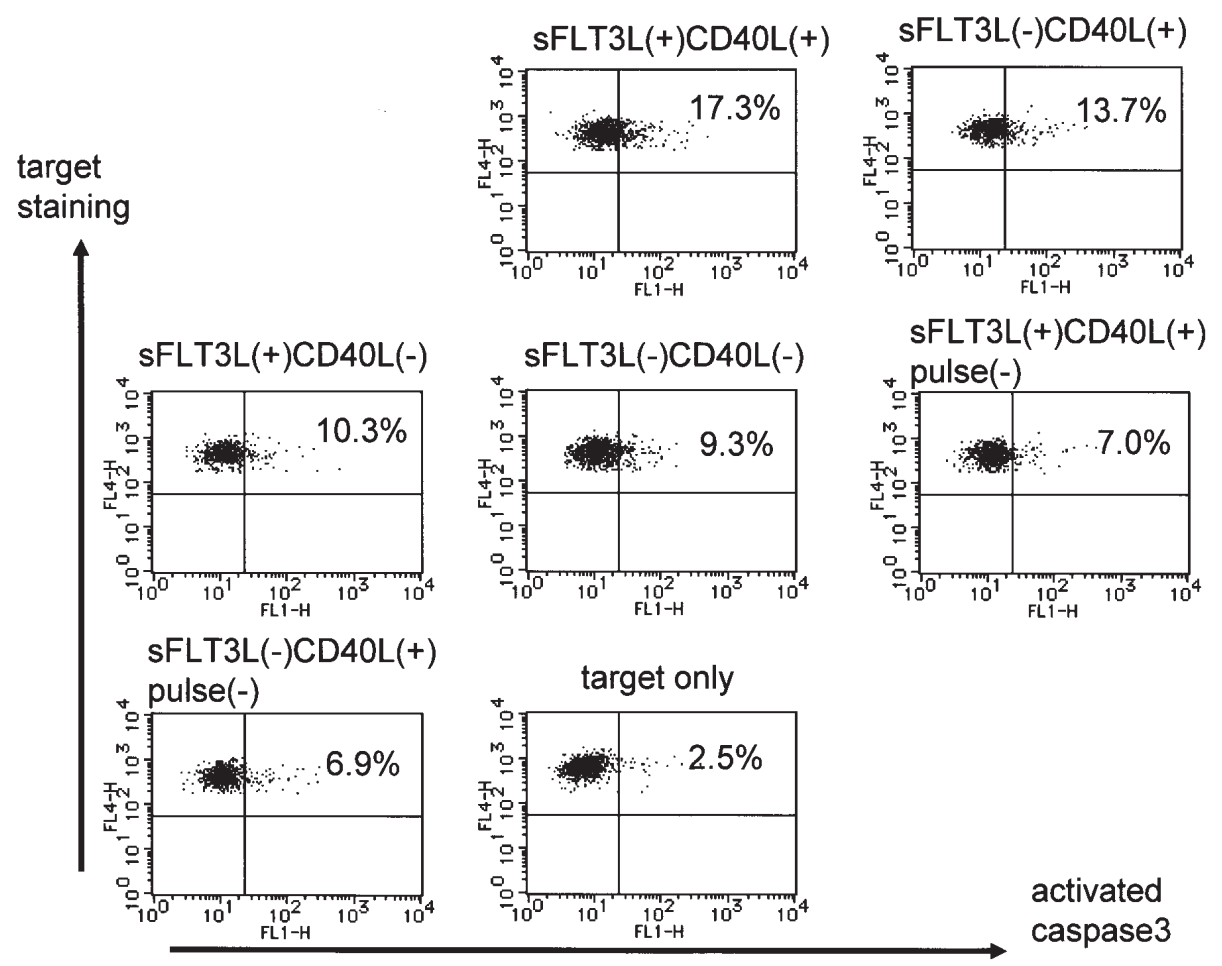

sFLT3L(-)CD40L(+)

Figure 6. mFLT3L stimulation to DCs enhanced the ability of DCs to induce cytotoxic activity of PBMCs when CD40L was added. PBMCs were co-cultured with DCs prepared as explained for Fig. 4. The cytotoxic activity of PBMCs against LCL was examined by flow cytometric cytotoxicity assay. (a) Apoptotic target cells were detected using a substrate of activated caspase 3. (b) Cytotoxic activity of PBMCs was not significantly enhanced by the mFLT3L stimulation to DCs (left). However, when CD40L was added during the co-culture of PBMCs and DCs, mFLT3L significantly enhanced the cytotoxic activity of PBMCs (right). At least 3 experiments were performed independently and the graph shows mean \pm SE. ${ }^{*}$ p $<0.05$, ${ }^{*}$ p $<0.01$. (c) Like mFLT3L, enhancement of cytotoxic activity induced by DCs generated with sFLT3L was apparent when CD40L was added during the co-culture of PBMCs and DCs. Two independent experiments were performed and similar results were obtained. Representative data are shown. 
a

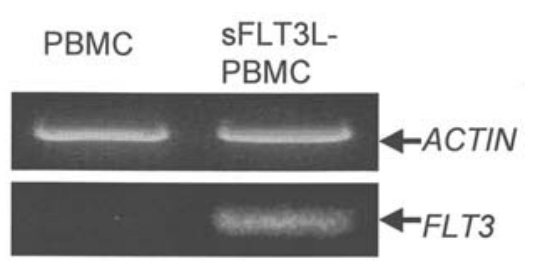

b

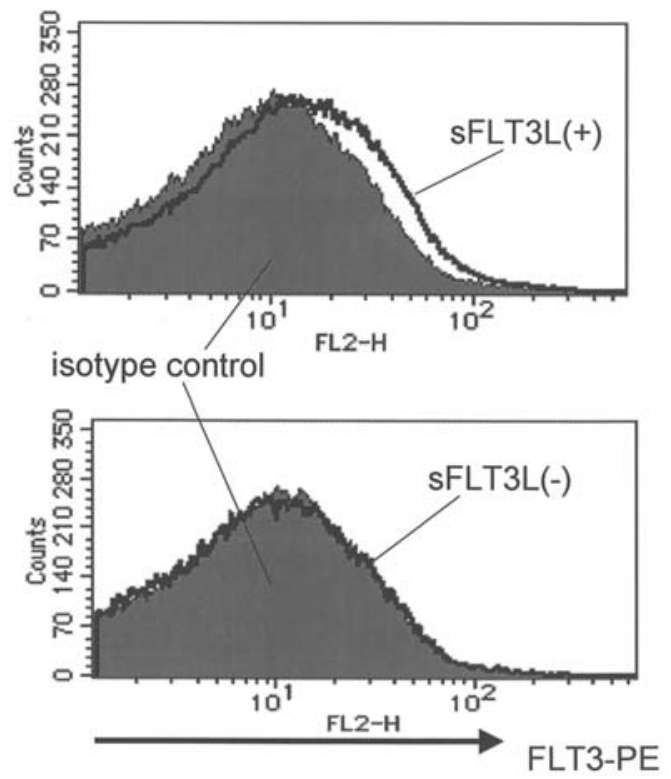

c

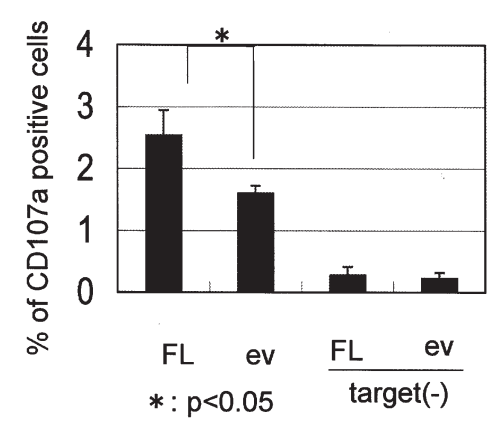

Figure 7. FLT3L induced FLT3 expression in CD56 $6^{+}$cells and enhanced cytotoxic activity of CD56 $6^{+}$cells. (a) Induction of FLT3 mRNA expression in PBMCs by sFLT3L addition was revealed by RT-PCR (30 cycles). Left, PBMCs without incubation. Right, PBMCs incubated for 7 days with FLT3L. (b) FLT3 protein expression in CD56 $6^{+}$cells after 7-day incubation with sFLT3L (upper). FLT3 expression was not detected in CD56 ${ }^{+}$cells without sFLT3L (lower). (c) Without DCs, activated CD56 ${ }^{+}$cells against LCL were increased by mFLT3L stimulation to PBMCs. At least 3 experiments were performed independently and the graph shows mean + SE.

(8-10). In accordance with these previous reports, we did not detect expression of FLT3 in purified peripheral monocytes. However, the expression of FLT3 was detected when differentiation of monocytes into DCs was induced by GM-CSF and IL-4. Moreover, FLT3 expression was augmented by addition of FLT3L in the course of DC generation. This is not likely the consequence of proliferation of hematopoietic progenitors, as the total cell number of the culture did not increase throughout the experimental course (data not shown) and the phenotype of cultured cells was uniformly that of DCs (Fig. 1b). Interestingly, addition of FLT3L somehow enhanced $\mathbf{a}$

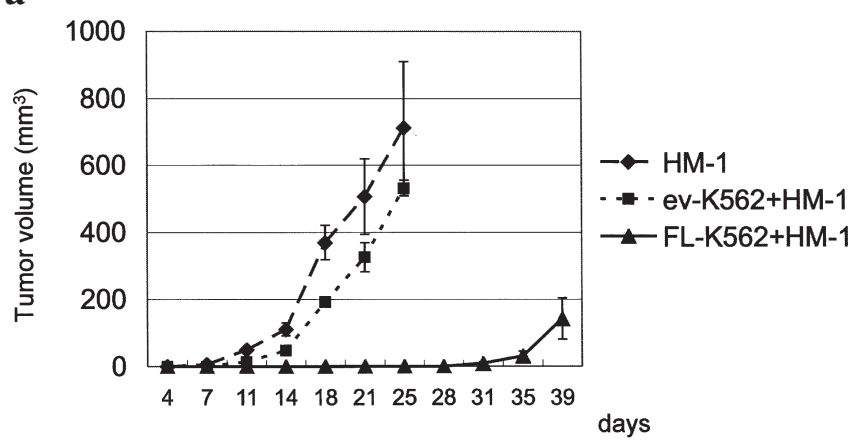

b

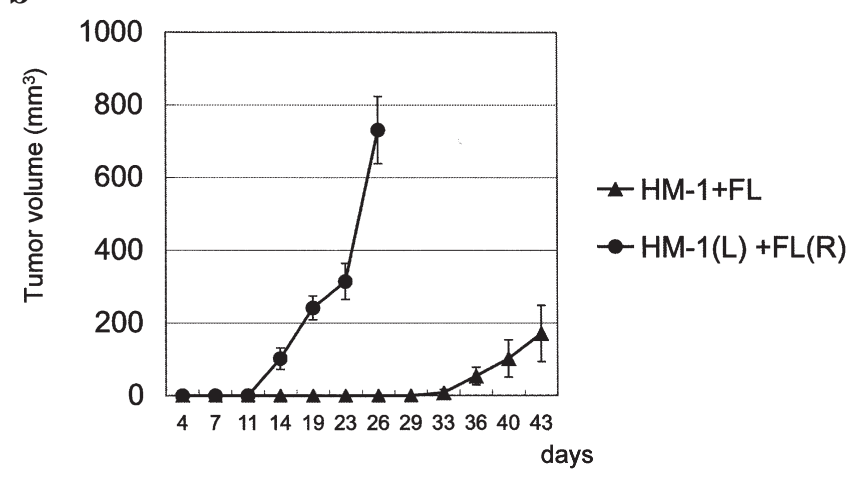

Figure 8. mFLT3L-transfected K562 cells exhibited anti-tumor activity against ovarian cancer. Anti-tumor effect of mFLT3L-K562 cells was examined using a murine ovarian cancer cell line HM-1 and syngenic B6C3F1 mice. (a) Irradiated empty vector-K562 cells (ם) or mFLT3L-K562 cells (ム) were mixed with HM-1 cells and inoculated. Otherwise, HM-1 cells only were inoculated $(\bullet)$. A marked anti-tumor effect was observed with the mFLT3L-K562 cells ( $n=4$ each). (b) HM-1 cells and irradiated mFLT3L-K562 cells were mixed and inoculated (A). Otherwise, HM-1 cells were inoculated into the left flank and mFLT3L-K562 cells into the right flank $(\bullet)(n=5$ each $)$. The graph shows mean \pm SEM.

induction of IFN- $\gamma$ secretion and CD107a mobilization (Figs. 4 and 5) during stimulation of effector cells. However, induction of cytotoxicity by CTLs co-cultured with the DCs was not observed unless CD40L was added along with FLT3L. At the same time, we found that CD40 expression in DCs was increased by the addition of FLT3L during the DC generation process (Figs. 2 and 3). In the case of hematopoietic progenitor cells, it is well known that FLT3-mediated responses are highly dependent on other growth factors combined with FLT3L. FLT3L stimulation of early hematopoietic progenitor cells without the addition of other growth factors results in monocyte differentiation without an apparent proliferative response. However, a vigorous proliferative response is produced if FLT3L is combined with growth factors such as IL-3, G-CSF or KIT ligand. Similarly, our results indicate that the immunostimulatory effect of FLT3L on DCs somehow depends on the presence of CD40L, suggesting that CD40CD40L interaction between DCs and T cells, one of the most potent immunostimulatory signals known between these two cell types (42), plays an important role in FLT3L action here.

It has been repeatedly reported that FLT3L has an antitumor effect in vivo in mouse models. Although systemic administration of FLT3L increases the number of DCs and NK cells, the anti-tumor effect of FLT3L is not necessarily explained by systemic stimulation of hematopoietic progenitor 
cells by FLT3L. Rather, a spatially distinct mechanism, including paracrine or autocrine stimulation of local primitive hematopoietic cells, appears to play a major role. In mouse models, inoculation of tumor cells (22-24) and DCs (26) expressing membrane bound FLT3L enhances anti-tumor immunity. In addition, local administration of FLT3L plasmids $(27,28)$ enhances the local Th1 reaction. In our study, FLT3Lexpressing K562 cells that were co-inoculated with HM-1 ovarian cancer cells locally also showed a tumor inhibitory effect. Although the precise mechanism of how the FLT3L/ FLT3 system works peripherally is yet to be elucidated, our in vitro data indicate that one of the possible mechanisms of the local anti-tumor effect of FLT3L may be the induced upregulation of CD40 in peripheral DCs. Indeed, the combination of FLT3L and CD40 ligand has been reported to be effective for tumor immunotherapy $(43,44)$.

NK cells are also a well-known target of FLT3L. It has been reported that locally expressed FLT3L enhances NK activity as well as DC function in vivo $(25,26)$. However, it is thought that mature NK cells do not express FLT3 and that FLT3L exerts its influence on NK cell progenitors. In this study, FLT3 expression was not detected in NK cells (Fig. 7a and b), and this is in accordance with previous reports (10). However, FLT3 expression was induced with FLT3L addition (Fig. 7a and b). As far as we know, there is no published data concerning the in vitro effect of FLT3L on NK cell activity, probably due to the presumed lack of expression of FLT3 in NK cells. Functionally, we examined CD107a mobilization in $\mathrm{CD}_{56}{ }^{+}$lymphocytes against LCL and found that NK activity was enhanced by the direct addition of FLT3L to PBMCs (Fig. 7c). This is the first report that FLT3L induces FLT3 expression in mature NK cells, and the underlying mechanism by which FLT3L acts on NK cells should be further examined.

In agreement with previous reports, our results showed the possibility of in vivo immunotherapy using FLT3L. As mentioned above, FLT3L might influence both peripheral blood NK cells and DCs in local circumstances, although it remains unclear whether administered FLT3L acts on these cells in the same manner as is found in vitro. In this study, we used irradiated K562 cells as a vehicle to deliver an immunostimulatory signal to exclude an allo-stimulatory effect (45). The more widely-pursued methods to stimulate an immune response by delivering a specific genetic signal(s) include transfecting DCs or tumor cells directly. However, ex vivo gene transfection to DCs is technically challenging (46). On the other hand, gene transfection into tumor cells is also difficult because of the need to culture tumor cells from each patient (47). Compared with these time- and laborconsuming methods, utilizing non-immune non-tumor cells as the target of gene transfection and the signal delivery carrier may provide a more efficient and realistic clinical use, if it has comparable efficacy to other methods. This study showed that FLT3L-transfected K562 cells serve as an immunostimulatory signal carrier both in vitro and in vivo. Further studies to compare its efficacy with other methods are necessary. The leukemia cell line, K562, may not be suitable in terms of clinical use. Therefore a proper target cell model should be carefully sought, which includes ex vivo culture of autologous normal cells that can be easily expanded and that are transfectable.
Previous reports suggested the risk that systemically administered FLT3L could induce immunotolerance in vivo by increasing immature DCs (17-21), although others reported contrary findings $(4,15)$. These conflicting data suggest that FLT3L may give rise to immunotolerance if administered systemically, and the enhancement of tumor immunity mainly depends on the circumstances where local immune response is evoked. Therefore, finding a method to elicit a potent immune reaction locally would be a key aspect in FLT3Lbased cancer therapy. Effective anti-tumor effects of FLT3L may be obtained when enhanced NK activity causes tumor cell death and secretion of TNF $\alpha$ from dead cells, followed by maturation and enhanced CD40 expression in DCs (48). On the other hand, ex vivo generation of DCs from monocytes with return to patients has been extensively tried for tumor immunotherapy $(49,50)$. Utilization of FLT3L for ex vivo generation of DCs may also be an attractive method in order to avoid tolerance.

In summary, our data indicate that FLT3L has an immunostimulatory effect on peripheral blood cells both in vitro and in vivo, suggesting that targeting of FLT3L to mature peripheral blood cells may be effective in cancer immunotherapy. Combination therapy with CD40 ligand would improve efficiency because FLT3L may induce CD40 expression in DCs as well as FLT3 expression in vitro.

\section{Acknowledgements}

We thank Dr Susan Murphy at Duke University Medical Center for her useful advice in preparation of the manuscript. We also thank Miss Michiko Muraoka for her contribution as a laboratory technician. This study was supported by Grantin-Aid for Scientific Research to S.F. (15209057), K.T. (17659514) and T.H. (17591729) from Japan Society for the Promotion of Science.

\section{References}

1. American Cancer Society: Cancer Facts and Figures 1995. Vol. 6. American Cancer Society, Atlanta, 1995.

2. Di Saia PJ and Creasman WT: In: Clinical Gynecology Oncology. Di Saia PJ and Creasman WT (eds). 5th edition. Mosby-Year Book, St. Louis, pp282-350, 1997.

3. Ozols RF, Rubin SC, Dembo AJ and Robboy SJ: Epithelial ovarian cancer. In: Principles and Practice of Gynecologic Oncology. Hoskins WJ, Perez CA and Young RC (eds). JP Lippincot, Philadelphia, p731, 1992.

4. Lynch DH, Andreasen A, Maraskovsky E, Whitmore J, Miller RE and Schuh JC: Flt3 ligand induces tumor regression and antitumor immune responses in vivo. Nat Med 3: 625-631, 1997.

5. Freedman RS, Vadhan-Raj S, Butts C, Savary C, Melichar B, Verschraegen C, Kavanagh JJ, Hicks ME, Levy LB, Folloder JK and Garcia ME: Pilot study of Flt3 ligand comparing intraperitoneal with subcutaneous routes on hematologic and immunologic responses in patients with peritoneal carcinomatosis and mesotheliomas. Clin Cancer Res 9: 5228-5237, 2003.

6. Disis ML, Rinn K, Knutson KL, Davis D, Caron D, dela Rosa C and Schiffman K: Flt3 ligand as a vaccine adjuvant in association with HER-2/neu peptide-based vaccines in patients with HER-2/ neu-overexpressing cancers. Blood 99: 2845-2850, 2002.

7. Silver DF, Hempling RE, Piver MS and Repasky EA: Flt-3 ligand inhibits growth of human ovarian tumors engrafted in severe combined immunodeficient mice. Gynecol Oncol 77: 377-382, 2000.

8. Visser M, Sonneveld RD, Willemze R and Landegent JE: Haemopoietic growth factor tyrosine kinase receptor expression profiles in normal haemopoiesis. Br J Haematol 94: 236-241, 1996. 
9. Rasko JE, Metcalf D, Rossner MT, Begley CG and Nicola NA: The flt3/flk-2 ligand: receptor distribution and action on murine haemopoietic cell survival and proliferation. Leukemia 9: 2058-2066, 1995

10. Karsunky H, Merad M, Cozzio A, Weissman IL and Manz MG: Flt3 ligand regulates dendritic cell development from Flt3+ lymphoid and myeloid-committed progenitors to Flt3+ dendritic cells in vivo. J Exp Med 198: 305-313,2003.

11. Rosnet O, Schiff C, Pebusque MJ, Marchetto S, Tonnelle C, Toiron Y, Birg F and Birnbaum D: Human FLT3/FLK2 gene: cDNA cloning and expression in hematopoietic cells. Blood 82: 1110-1119, 1993

12. Namikawa R, Muench MO, de Vries JE and Roncarolo MG: The FLK2/FLT3 ligand synergizes with interleukin-7 in promoting stromal-cell-independent expansion and differentiation of human fetal pro-B cells in vitro. Blood 87: 1881-1890, 1996.

13. Veiby OP, Jacobsen FW, Cui L, Lyman SD and Jacobsen SE: The flt-3 ligand promotes the survival of primitive hemopoietic progenitor cells with myeloid as well as B lymphoid potential. Suppression of apoptosis and counteraction by TNF-alpha and TGF-beta. J Immunol 157: 2953-2960, 1996.

14. Smith JR, Thackray AM and Bujdoso R: Reduced herpes simplex virus type 1 latency in Flt-3 ligand-treated mice is associated with enhanced numbers of natural killer and dendritic cells. Immunology 102: 352-358, 2001.

15. Tourkova IL, Yamabe K, Chatta G, Shurin GV and Shurin MR: NK cells mediate Flt3 ligand-induced protection of dendritic cell precursors in vivo from the inhibition by prostate carcinoma in the murine bone marrow metastasis model. J Immunother 26: 468-472, 2003.

16. Masten BJ, Olson GK, Kusewitt DF and Lipscomb MF: Flt3 ligand preferentially increases the number of functionally active myeloid dendritic cells in the lungs of mice. J Immunol 172: 4077-4083, 2004

17. Chilton PM, Rezzoug F, Fugier-Vivier I, Weeter LA, Xu H, Huang Y, Ray MB and Ildstad ST: Flt3-ligand treatment prevents diabetes in NOD mice. Diabetes 53: 1995-2002, 2004

18. Edwan JH, Perry G, Talmadge JE and Agrawal DK: Flt-3 ligand reverses late allergic response and airway hyper-responsiveness in a mouse model of allergic inflammation. J Immunol 172: 5016-5023, 2004

19. Morin J, Faideau B, Gagnerault MC, Lepault F, Boitard C and Boudaly S: Passive transfer of flt-3L-derived dendritic cells delays diabetes development in NOD mice and associates with early production of interleukin (IL)-4 and IL-10 in the spleen of recipient mice. Clin Exp Immunol 134: 388-395, 2003.

20. Teshima T, Reddy P, Lowler KP, KuKuruga MA, Liu C, Cooke KR and Ferrara JL: Flt3 ligand therapy for recipients of allogeneic bone marrow transplants expands host CD8 alpha(+) dendritic cells and reduces experimental acute graft-versus-host disease. Blood 99: 1825-1832, 2002.

21. Miller G, Pillarisetty VG, Shah AB, Lahrs S and DeMatteo RP: Murine Flt3 ligand expands distinct dendritic cells with both tolerogenic and immunogenic properties. J Immunol 170: 3554-3564, 2003.

22. Alsheikhly AR, Zweiri J, Walmesley AJ, Watson AJ and Christmas SE: Both soluble and membrane-bound forms of Flt3 ligand enhance tumor immunity following 'suicide' gene therapy in a murine colon carcinoma model. Cancer Immunol Immunother 53: 946-954, 2004.

23. Chen K, Braun S, Lyman S, Fan Y, Traycoff CM, Wiebke EA, Gaddy J, Sledge G, Broxmeyer HE and Cornetta K: Antitumor activity and immunotherapeutic properties of Flt3-ligand in a murine breast cancer model. Cancer Res 57: 3511-3516, 1997.

24. Sivanandham M, Stavropoulos CI, Kim EM, Mancke B and Wallack MK: Therapeutic effect of colon tumor cells expressing FLT-3 ligand plus systemic IL-2 in mice with syngeneic colon cancer. Cancer Immunol Immunother 51: 63-71, 2002.

25. Braun SE, Chen K, Blazar BR, Orchard PJ, Sledge G, Robertson MJ, Broxmeyer HE and Cornetta K: Flt3 ligand antitumor activity in a murine breast cancer model: a comparison with granulocyte-macrophage colony-stimulating factor and a potential mechanism of action. Hum Gene Ther 10: 2141-2151, 1999.

26. Liu Y, Huang H, Chen Z, Zong L and Xiang J: Dendritic cells engineered to express the Flt3 ligand stimulate type I immune response, and induce enhanced cytoxic $\mathrm{T}$ and natural killer cell cytotoxicities and antitumor immunity. J Gene Med 5: 668-680, 2003.
27. Sang H, Pisarev VM, Munger C, Robinson S, Chavez J, Hatcher L, Parajuli P, Guo Y and Talmadge JE: Regional, but not systemic recruitment/expansion of dendritic cells by a pluronic-formulated Flt3-ligand plasmid with vaccine adjuvant activity. Vaccine 21: 3019-3029, 2003.

28. Kataoka K, McGhee JR, Kobayashi R, Fujihashi K, Shizukuishi S and Fujihashi K: Nasal Flt3 ligand cDNA elicits CD11c+CD8+ dendritic cells for enhanced mucosal immunity. J Immunol 172: 3612-3619, 2004.

29. Pabst R, Luhrmann A, Steinmetz I and Tschernig T: A single intratracheal dose of the growth factor Fms-like tyrosine kinase receptor-3 ligand induces a rapid differential increase of dendritic cells and lymphocyte subsets in lung tissue and bronchoalveolar lavage, resulting in an increased local antibody production. J Immunol 171: 325-330, 2003.

30. Nilsson K and Klein G: Phenotypic and cytogenetic characteristics of human B-lymphoid cell lines and their relevance for the etiology of Burkitt's lymphoma. Adv Cancer Res 37: 319-380, 1982 .

31. Braun SE, Aronica SM, Ge Y, Takahira H, Etienne-Julan M, Lu L, Minden MD, Lyman SD and Broxmeyer HE: Retroviral mediated gene transfer of Flt3 ligand enhances proliferation and MAP kinase activity of AML5 cells. Exp Hematol 25: 51-56, 1997.

32. Rubio V, Stuge TB, Singh N, Betts MR, Weber JS, Roederer M and Lee PP: Ex vivo identification, isolation and analysis of tumor-cytolytic T cells. Nat Med 9: 1377-1382, 2003.

33. Betts MR, Brenchley JM, Price DA, De Rosa SC, Douek DC, Roederer M and Koup RA: Sensitive and viable identification of antigen-specific CD8+ T cells by a flow cytometric assay for degranulation. J Immunol Methods 281: 65-78, 2003.

34. Lacey SF, Martinez J, Gallez-Hawkins G, Thao L, Longmate J, Haq W, Spielberger R, Forman SJ, Zaia JA and Diamond DJ: Simultaneous reconstitution of multiple cytomegalovirusspecific CD8+ cell populations with divergent functionality in hematopoietic stem-cell transplant recipients. J Infect Dis 191: 977-984, 2005.

35. Lyman SD, James L, Johnson L, Brasel K, de Vries P, Escobar SS, Downey H, Splett RR, Beckmann MP and McKenna HJ: Cloning of the human homologue of the murine flt 3 ligand: a growth factor for early hematopoietic progenitor cells. Blood 83: 2795-2801, 1994.

36. McKenna HJ: Role of hematopoietic growth factors/Flt3-ligand in expansion and regulation of dendritic cells. Curr Opin Hematol 8: 149-154, 2001

37. Antonysamy MA and Thomson AW: Flt3-ligand (FL) and its influence on immune reactivity. Cytokine 12: 87-100, 2000.

38. Brasel K, McKenna HJ and Morrissey PJ: Hematologic effects of Flt3-ligand in vivo in mice. Blood 88: 2004-2012, 1996.

39. Pulendran B, Banchereau J, Burkeholder S, et al: Flt3-ligand and granulocyte colony-stimulating factor mobilize distinct human dendritic cell subsets in vivo. J Immunol 165: 566-572, 2000.

40. McKenna HJ, Stocking KL, Miller RE, Brasel K, De Smedt T, Maraskovsky E, Maliszewski CR, Lynch DH, Smith J, Pulendran B, Roux ER, Teepe M, Lyman SD and Peschon JJ: Mice lacking flt3 ligand have deficient hematopoiesis affecting hematopoietic progenitor cells, dendritic cells, and natural killer cells. Blood 95: 3489-3497, 2000.

41. Brossart P, Grunebach F, Stuhler G, Reichardt VL, Mohle R, Kanz $L$ and Brugger W: Generation of functional human dendritic cells from adherent peripheral blood monocytes by CD40 ligation in the absence of granulocyte-macrophage colony-stimulating factor. Blood 92: 4238-4247, 1998.

42. O'Sullivan B and Thomas R: CD40 and dendritic cell function. Crit Rev Immunol 23: 83-107, 2003.

43. Borges L, Miller RE, Jones J, Ariail K, Whitmore J, Fanslow W and Lynch DH: Synergistic action of fms-like tyrosine kinase 3 ligand and CD40 ligand in the induction of dendritic cells and generation of antitumor immunity in vivo. J Immunol 163: 1289-1297, 1999

44. Yanagi K, Nagayama Y, Nakao K, Saeki A, Matsumoto K, Ichikawa $\mathrm{T}$, Ishikawa $\mathrm{H}$, Hamasaki $\mathrm{K}$, Ishii $\mathrm{N}$ and Eguchi $\mathrm{K}$ : Immuno-gene therapy with adenoviruses expressing fms-like tyrosine kinase 3 ligand and CD40 ligand for mouse hepatoma cells in vivo. Int J Oncol 22: 345-351, 2003.

45. Maus MV, Thomas AK, Leonard DG, Allman D, Addya K, Schlienger K, Riley JL and June CH: Ex vivo expansion of polyclonal and antigen-specific cytotoxic $\mathrm{T}$ lymphocytes by artificial APCs expressing ligands for the T-cell receptor, CD28 and 4-1BB. Nat Biotechnol 20: 143-148, 2002. 
46. Kim JV, Latouche JB, Riviere I and Sadelain M: The ABCs of artificial antigen presentation. Nat Biotechnol 22: 403-410, 2004.

47. Peehl DM: Are primary cultures realistic models of prostate cancer? J Cell Biochem 91: 185-195, 2004.

48. Ardavin C, Martinez del Hoyo G, Martin P, Anjuere F, Arias CF, Marin AR, Ruiz S, Parrillas V and Hernandez H: Origin and differentiation of dendritic cells. Trends Immunol 22: 691-700, 2001 .
49. Fong L, Brockstedt D, Benike C, Wu L and Engleman EG: Dendritic cells injected via different routes induce immunity in cancer patients. J Immunol 166: 4254-4259, 2001.

50. Kugler A, Stuhler G, Walden P, Zoller G, Zobywalski A, Brossart P, Trefzer U, Ullrich S, Muller CA, Becker V, Gross AJ, Hemmerlein B, Kanz L, Muller GA and Ringert RH: Regression of human metastatic renal cell carcinoma after vaccination with tumor cell-dendritic cell hybrids. Nat Med 6: 332-336, 2000. 